\title{
Aneurysmal right coronary with fistula to the coronary sinus combined with severe stenosis of the left anterior descending artery: A snake on the heart
}

\author{
Lei Yu, MD, Enyi Shi, MD, PhD, and Tianxiang Gu, MD, PhD
}

\begin{abstract}
A 68-year-old man was referred to our hospital with precordialgia and palpitation. A continuous murmur over the left sternal border at the fourth intercostal space was discovered. Echocardiography and multidetector computed tomography suggested the presence of an aneurysmal right coronary artery (RCA) and fistula into the coronary sinus (CS) (Figure 1, $A$ to $D$ ). Three-dimensional computed tomography showed that the aneurysmal RCA had many loops over its route just like a snake on the heart (Figure 1, $E$ and $F$ ). Coronary angiography disclosed an aneurysmal RCA with a fistula into the CS (Figure 2, A) and an $80 \%$ stenosis of the left anterior descending artery (LAD) coronary artery. Surgery was performed through a sternotomy with cardiopulmonary bypass. After the pericardial cavity was exposed, a giant and circumvolved RCA was seen (Figure 2, B). During the cardioplegic infusion, a CS fistula was manually compressed. After cardioplegia, the
\end{abstract}

fistula was identified as a 16-mm hole at the roof of the CS ostium. Although the main body of the RCA expanded too much, there were no remarkable branches worth bypassing except the posterior descending coronary artery. After dividing all marginal branches, we resected the body of the RCA before the posterior descending coronary artery. The RCA was sutured directly proximal to the point where it merged and entered the CS. The CS size was reduced (Figure 2,C). The posterior descending coronary artery and LAD were bypassed with 2 saphenous vein grafts. Three-dimensional computed tomography revealed that all grafts were patent 1 year later (Figure 2, D).

Aneurysmal RCA with drainage into the CS combined severe stenosis of the LAD, as in the present case, has not been seen. Owing to the progress made in cardiac imaging procedures, this challenging patient could be identified and surgical repair was a reasonable treatment of choice.

\footnotetext{
From the Department of Cardiac Surgery, the First Affiliated Hospital of China Medical University, Shenyang, People's Republic of China.

Disclosures: Authors have nothing to disclose with regard to commercial support.

Received for publication May 17, 2011; accepted for publication May 23, 2011; available ahead of print July 4, 2011.

Address for reprints: Tianxiang Gu, MD, PhD, Department of Cardiac Surgery, The First Affiliated Hospital, China Medical University, Shenyang, People's Republic of China, 110001 (E-mail: cmugtx@ sina.com).

J Thorac Cardiovasc Surg 2011;142:937-9

$0022-5223 / \$ 36.00$

Copyright (c) 2011 by The American Association for Thoracic Surgery

doi:10.1016/j.jtcvs.2011.05.020
} 

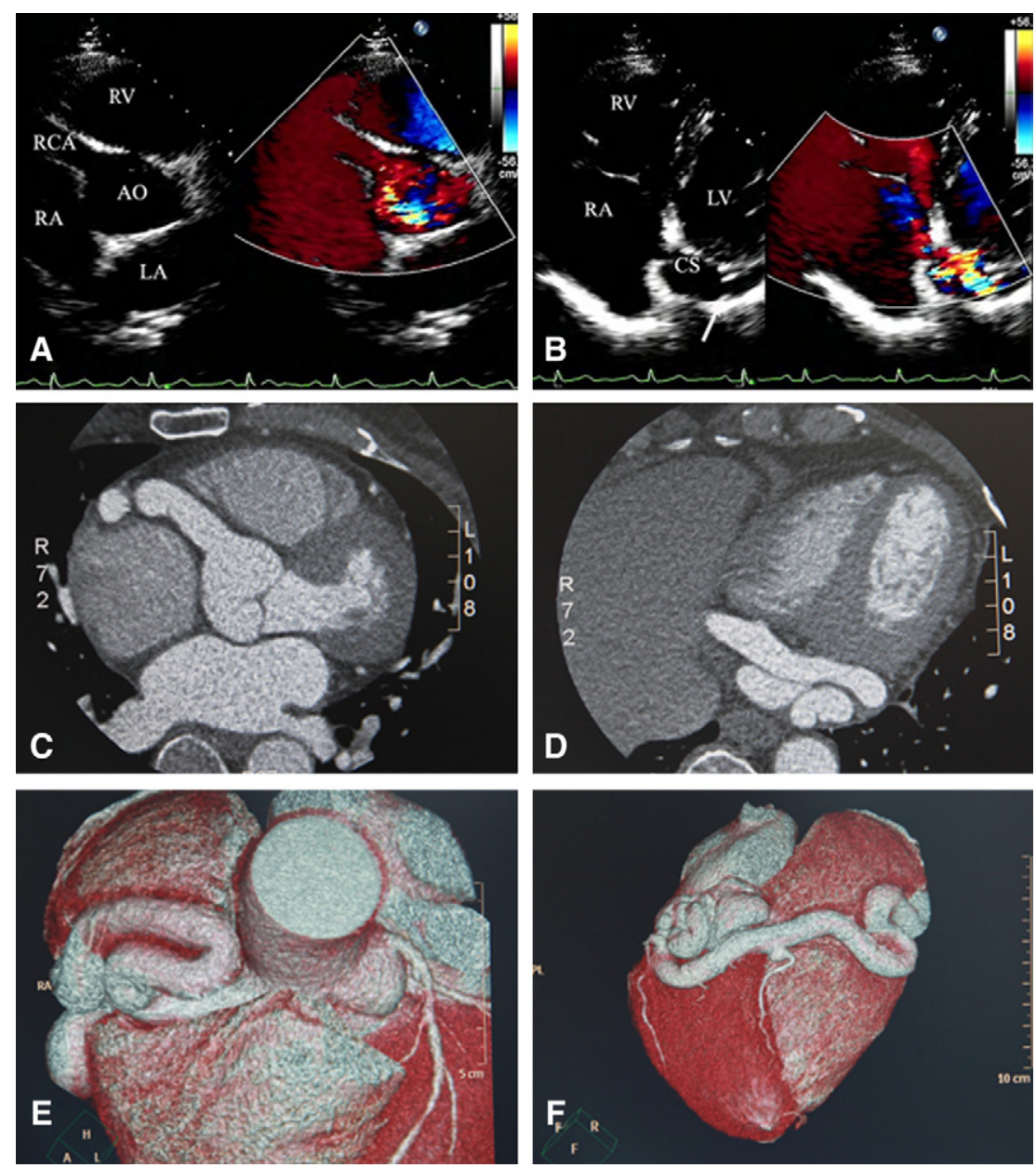

FIGURE 1. A and B, Echocardiography revealed the dilated right coronary artery $(R C A)$ and fistula into the coronary sinus. C and D, Multidetector computed tomography demonstrating the extremely enlarged RCA. E and F, Three-dimensional computed tomography showed large circumvolved RCA just like a snake on his heart. $A O$, Ascending aorta; $L A$, left atrium; $L V$, left ventricle; $R A$, right atrium; $R V$, right ventricle; $C S$, coronary sinus. 

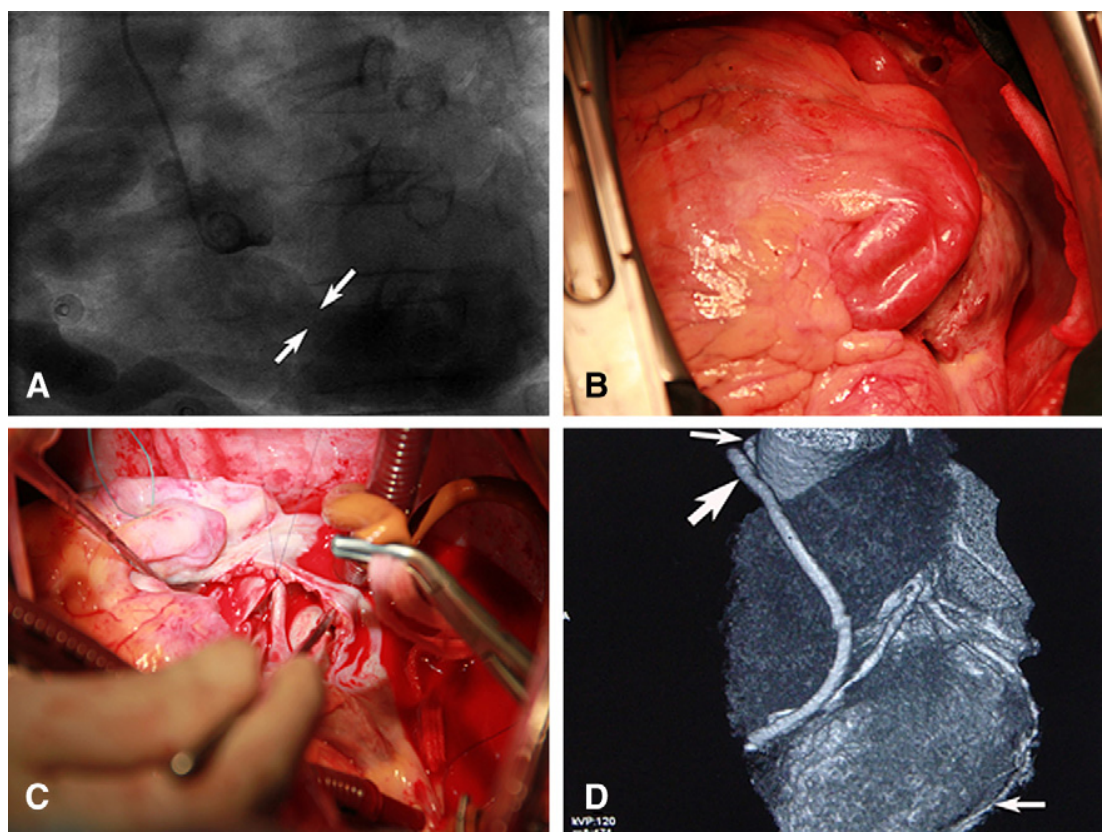

FIGURE 2. A, Coronary angiography shows the enlarged right coronary artery with the fistula (arrows) originating from right coronary artery ( $R C A$ ). B, Operational view. Aneurysmal RCA is seen before cardiopulmonary bypass. C, Intraoperative photograph. The coronary sinus size was reduced. D, Postoperative 3-dimensional computed tomography scan revealed the saphenous vein grafts between the aorta and left anterior descending (large arrow) and right coronary arteries (small arrow) were patent. 